\title{
(7) \\ Inventory Management of Drugs at a Secondary Level Hospital Associated with Ballabgarh HDSS- An Experience from North India
}

\author{
Shashi Kant ${ }^{1,2}$ Partha Haldar ${ }^{1,2}$, Arvind Singh ${ }^{1}$, Ankita Kankaria ${ }^{1,3}$ \\ ${ }^{1}$ Centre for Community Medicine, All India Institute of Medical Sciences, New Delhi, India. \\ ${ }^{2}$ Comprehensive Rural Health Services Project, Ballabgarh HDSS, Faridabad, Haryana, India \\ ${ }^{3}$ School of Public Health, PGIMER, Chandigarh, India.
}

\begin{abstract}
Introduction: Effective management of medical stores entails supervision of important drugs, and priority setting in purchase and distribution of drugs. Studies have mainly explored the inventory management at tertiary-care settings. Objective of this study was to explore the optimal drug inventory management technique suitable for a secondary care hospital. Method: Procurement, consumption, and expenditure data of drugs was analysed at the secondary level sub-district hospital attached to the Comprehensive Rural Health Services Project (CRHSP), of the Ballabgarh Health and Demographic Surveillance system, in Northern India. The annual procurement of, and expenditure incurred on drugs for financial year 2012-13 was analysed using inventory control techniques, based on expenditure (ABC), criticality (VED), and a combination matrix of ABC-VED. Results: Total annual expenditure on 182 drugs was Rs $6,495,785$ amounting to $21 \%$ of hospital budget for the financial year $2013-14$. ABC analysis revealed $10.4 \%, 19.8 \%$ and $69.8 \%$ drugs as A, B and C category, respectively, accounting for $69.7 \%, 21.2 \%$ and $9.1 \%$ of annual expenditure. VED analysis showed $31.9 \%, 53.3 \%$ and $14.8 \%$ items as $\mathrm{V}, \mathrm{E}$, and D category, respectively, accounting for $12.1 \%, 84.5 \%$ and $3.4 \%$ of annual expenditure. On ABC-VED matrix analysis, $40.6 \%, 46.7 \%$ and $12.7 \%$ drugs were found to be category I, II and III, respectively, accounting for $77 \%, 21.8 \%$ and $1.2 \%$ of annual expenditure. Conclusion: Using ABC-VED matrix could achieve both time saving and assured availability of needed drugs by closely supervising category I that comprised $40 \%$ of all drugs. ABC-VED matrix analysis system is an optimal drug inventory management system at a secondary health care setting.
\end{abstract}

Key words: ABC analysis, ABC-VED matrix, Inventory management, Secondary Level, VED analysis.

\begin{tabular}{|c|c|}
\hline \multicolumn{2}{|c|}{ Access this article online } \\
\hline Journal Sponsor & \multirow[b]{2}{*}{$\begin{array}{l}\text { Website: } \\
\text { www.jyoungpharm.org }\end{array}$} \\
\hline \multirow{2}{*}{ www.phcog net } & \\
\hline & DOI: 10.5530/jyp.2015.2.9 \\
\hline
\end{tabular}

\section{INTRODUCTION}

An inventory is a detailed itemized list of assets held by an organization or institution like goods in stock, drugs and equipment. It is a method of maintaining stock of drugs at a level of lowest purchasing and stocking cost, and without interference with supply. ${ }^{1}$ Procurement of material and supplies including drugs, account for nearly

\footnotetext{
*Address for correspondence:

Mr. Partha Haldar, Centre for Community Medicine, Old OT Block, All India Institute of Medical Sciences, New Delhi 110029, India.

Email: drparthohaldar@gmail.com
} 
one third of the hospital budget. ${ }^{2}$ Effective and efficient management of medical stores entails close supervision of important drugs, prevention of pilferage, and priority setting in purchase and distribution of drugs. Review and control measures for expensive drugs can bring about $20 \%$ savings in medical store budget. ${ }^{3}$ An efficient inventory control system would help optimize use of resources and eventually help improve patient care, by ensuring availability of essential stocks and preventing stock-outs. ${ }^{4}$ This is of particular importance in a resource constraint setting like India where resources are limited, and existing resources must be utilized appropriately. ${ }^{5}$

There are various approaches for inventory management. ${ }^{2}$ These are ABC (Always, Better, Control), VED (Vital, Essential, Desirable), FSN (Fast-moving, Slow-moving, Non-moving, SDE (Scarce, Difficult, Easy), HML (High, Medium, Low) and SOS (Season-Off-Season). ${ }^{1}$

Among these $\mathrm{ABC}, \mathrm{VED}$, and $\mathrm{ABC}-\mathrm{VED}$ matrix analysis are applied commonly. The analytic perspective of each of these approaches is different. While the ABC is mainly based on an annual cost of drugs, the analytical components for the VED comprise both vitalness, and criticality of drugs. Sometimes, ABC or VED analysis alone is not enough, and carry certain limitations. $A B C$ is based mainly on monetary value and compromises on essentiality of a drug. In a hospital, a drug may be of low monetary value but may be critical for patient care. E.g. injection Avil. So, to consider criticality of a drug, VED analysis should also be considered. However, considering VED alone carries a risk of some desirable drugs despite being costly could get included as a priority drug. To overcome these limitations an ABC-VED matrix is prepared, and drugs are categorised as Category I, II and III. (Box 1). This effectively makes use of the complimentarily of each procedure.

Numbers of studies are available which have explored the inventory management at a tertiary care setting. However, similar work in a secondary care setting is scarce. Objective of this study was to explore the optimal drug inventory management technique suitable for a secondary care hospital. We hoped that this study could be useful for hospital managers of secondary care hospitals in improving the quality of inventory management.

\section{MATERIAL AND METHODS}

We did a secondary analysis of the data on procurement, consumption, and expenditure on drugs at the secondary care hospital (sub-district level) attached to the Comprehensive Rural Health Services Project (CRHSP), of the Centre for Community Medicine, All India Institute of Medical Sciences (AIIMS), New Delhi, situated at Ballabgarh Taluk of Faridabad district in the state of Haryana in Northern India. The CRHSP is a collaborative project of AIIMS, New Delhi, and the State Government of Haryana. The project caters to a population base of around 92,000 that is known as the Ballabgarh Health and Demographic Surveillance System (HDSS). ${ }^{6}$ This secondary care 50 bedded hospital was situated on the Delhi-Agra National-Highway number 2, at a distance of approximately 40 kilometres from New Delhi. The hospital provided daily outpatient curative services for specialties of Medicine, Surgery, OBG, Paediatrics, Ophthalmology, Psychiatry, Dental, and AYUSH. Limited-day OPDs for the specialties of ENT, Orthopaedics, Physical Medicine and Rehabilitation. Preventive services were provided in the form of antenatal care (ANC) and immunisation. Inpatient services were available for institutional delivery, OBG, Medicine, Surgery, Ophthalmology and Paediatrics. The outpatient care attendance in year 2013 was approximately 225,000 . There was dual source of supply of drugs i.e. from the AIIMS, as well as from Government of Haryana. The supply chain from Government of Haryana was, however, not under the administrative control of CRHSP. The vendors for AIIMS had to supply the drugs within 45 days of placement of an order. There was penalty clause for delayed supply.

\section{Data collection}

The data was collected for a period of one financial year from 1-4-2012 to 31-3-2013. All the oral and parenteral drugs were included for the analysis. Quantity of drugs procured by the hospital was obtained from the stock register. Expenditure on procurement of a particular drug was calculated based on its source of supply i.e. whether it was sourced from AIIMS, or from Government of Haryana. The cost of drug procured through AIIMS was based on supply order. The updated rate list available at the online drug inventory system of Government of Haryana was used for the drugs supplied by Government of Haryana. ${ }^{7}$ For drugs that were purchased locally, the cost mentioned in the sales bill was considered.

\section{$A B C, V E D$ analysis, and the ABC-VED Matrix}

For $\mathrm{ABC}$ analysis, expenditure on individual drug was arranged in a descending order, and the cumulative cost was calculated. Drugs accounting for the first $70 \%$ of the cumulative cost were labelled as category "A", drugs accounting for the next $20 \%$ of cumulative cost as category "B", and finally the remaining drugs were labelled as category " $\mathrm{C}$ ".

Journal of Young Pharmacists Vol 7 • Issue 2 • Apr-Jun 2015 


\begin{tabular}{|c|c|c|c|}
\hline $\mathrm{VED} / \mathrm{ABC}$ & $\mathbf{A}$ & $\mathbf{B}$ & C \\
\hline $\mathbf{V}$ & ---------- & ---------- & ---------- \\
\hline $\mathbf{E}$ & ---------- & & \\
\hline $\mathbf{D}$ & --------- & & \\
\hline
\end{tabular}

\section{Category I $\quad$ - Category II $\square$ Category II}

Figure 1: $A B C-V E D$ Matrix

\begin{tabular}{|c|c|c|c|}
\hline Analysis type & Category & $\begin{array}{l}\text { Number of drugs } \\
\text { (percent of total } \\
\text { drugs) }\end{array}$ & $\begin{array}{l}\text { Expenditure in Rupees } \\
\text { (percent of total } \\
\text { expenditure) }\end{array}$ \\
\hline \multirow[t]{3}{*}{$A B C$ analysis } & A & $19(10.4)$ & $45,25,426(69.7)$ \\
\hline & B & $36(19.8)$ & $13,77,350(21.2)$ \\
\hline & C & $127(69.8)$ & $5,93,009(9.1)$ \\
\hline \multicolumn{2}{|c|}{ Total (ABC) } & $182(100)$ & $64,95,785(100)$ \\
\hline \multirow[t]{4}{*}{ VED analysis } & V & $58(31.9)$ & $7,85,712(12.1)$ \\
\hline & $E$ & $97(53.3)$ & $54,89,387(84.5)$ \\
\hline & D & $27(14.8)$ & $2,20,685(3.4)$ \\
\hline & Total (VED) & $182(100)$ & $64,95,785(100)$ \\
\hline
\end{tabular}

For VED analysis, list of drugs procured during the study period were given to the specialists who were providing clinical services at this hospital. They were asked to classify the drugs into three categories viz. vital, essential, and desirable. In case of difference of opinion regarding VED classification among specialists, reference was made to the Indian Public Health Standards Guidelines. ${ }^{8}$ For those drugs where the classification was still unclear, the arbitration and final classification was accorded by two authors (AKS and $\mathrm{AK})$. The expenditure incurred on $\mathrm{V}, \mathrm{E}$ and $\mathrm{D}$ drugs were calculated as percentages of the total expenditures. The ABC-VED matrix was cross-tabulated and categorised as I, II and III (Figure 1). Category I constituted AV, BV, CV $\mathrm{AE}$ and $\mathrm{AD}$ drugs, category II constituted $\mathrm{BE}, \mathrm{CE}$ and $\mathrm{BD}$ drugs, and category III constituted CD drugs. ${ }^{4}$

\section{RESULTS}

Table 2: Distribution of drugs as Category I, II and III drugs and expenditure in each category $(\mathrm{n}-182)$

$\begin{array}{lcc}\text { Category of drugs } & \begin{array}{l}\text { Number of drugs } \\ \text { (percent of drugs) }\end{array} & \begin{array}{l}\text { Expenditure in } \\ \text { Rupees (proportion of } \\ \text { total expenditure) }\end{array} \\ \text { I } & 74(40.6) & 50,04,474(77 \%) \\ \text { II } & 85(46.7) & 14,17,215(21.8 \%) \\ \text { III } & 23(12.7) & 74,094(1.2 \%) \\ \text { Total } & 182(100) & 64,95,784(100 \%)\end{array}$

A total of 182 drugs were included in the analysis. The distribution of drugs based on cumulative cost was tabulated as category $\mathrm{A}, \mathrm{B}$ and $\mathrm{C}$. There were a total of 19 drugs in category A, 36 in category B, and 127 in category $\mathrm{C}$. Thus, ten percent of the drugs cost $70 \%$ of the expenditure, while $70 \%$ of the drugs cost only $10 \%$ of the expenditure (Table 1). A total of 58 drugs were classified as category "V", 97 as category "E" and 27 as category "D". Around $12 \%$ of budget was spent on category V, $84.5 \%$ on category $\mathrm{E}$ and $3.4 \%$ on category $\mathrm{D}$ drugs (Table 1). Though one third of the drugs were considered vital, the expenditure incurred on them was only $12 \%$. Only small proportions (14.8\%) of drugs were classified as desirable. Expenditure incurred on desirable drugs was minuscule (3.4\%). In ABC-VED matrix, around $40 \%$ of drugs were in category I, $47 \%$ in category II, and $13 \%$ in category III. The expenditure in category I, II and III were $77 \%, 22 \%$ and $1 \%$ of total expenditure respectively (Table 2 ).

\section{DISCUSSION}

We present an inventory analysis of drugs used at a secondary level hospital using ABC, VED, and an ABC-VED matrix based approaches. The total cost incurred for procurement of drugs in this secondary level hospital was Indian Rupees $6,495,785$ amounting to nearly $21 \%$ of the total hospital 
budget for the financial year 2013-14. Proportionate expenditure on drugs in our study was lower than previous published studies which reported annual drug expenditure as $33 \%$ of their annual health expenditure. ${ }^{3,4}$ However, these other studies were done in a tertiary level facilities.

We found that $10 \%$ of drugs were in category A. This finding was comparable to studies conducted at tertiary level hospitals where category A drugs were reported to be from $11 \%$ to $18 \%{ }^{3,4}$ Similar to others studies there were around $20 \%$ of drugs in category $\mathrm{B}$, and around $70 \%$ of drugs in category $\mathrm{C}^{3,4}$ If we were to manage drug inventory based solely on $\mathrm{ABC}$ analysis, supervision of only 19 drugs would have resulted in control over approximately $70 \%$ of the drug budget. The managers could save their time by ignoring to manage $70 \%$ of drugs which cost only $10 \%$ of the total expenditure on drugs.

In our study, $32 \%$ of drugs were categorised as vital i.e. category V. In other studies it had varied from $5 \%$ to $24 \%$. Around $54 \%$ of drugs were in category E in present study, whereas it ranged from $39 \%$ to $60 \%$ in other studies. ${ }^{3,4}$ Gross difference was noted in category $\mathrm{D}$ drugs. In our study category $\mathrm{D}$ drugs comprised of $15 \%$ whereas in other studies it was between $29 \%$ and $43 \% .^{2-4}$ This difference might be due to the type of study setting, as well as, due to the conscious decision of the managers to stock category $\mathrm{D}$ drugs in their facility. Ours being a secondary health care facility, the proportion of desirable drugs was expected to be lower than those in a tertiary health care setting. If we were to manage drug inventory based solely on VED analysis, then we would have needed supervision of all the 'vital' and 'essential' drugs. The hospital could not afford to have stock-outs of these drugs. In the present case, this would have meant supervision of virtually all the drugs $(85 \%)$. Thus, VED analysis alone would have failed to be an efficient tool for inventory management. Our expenditure on 'desirable' drugs was minuscule (3.4\%). In a resource constraint setting it is necessary that most of the budget was spent on the 'vital' and 'essential' category of the drugs rather than the 'desirable' category.

On ABC-VED matrix analysis, drugs were categorised as I, II and III. We had $40 \%$ of the drugs as category I, whereas in other studies it had varied from $21 \%$ to $30 \%$. For category II drugs our findings ( $47 \%$ of drugs) was similar to other studies ( $42 \%$ to $57 \%$ ). However, in category III, we had $13 \%$ of drugs while in other studies it varied from $23 \%$ to $36 \%$. Major (77\%) cost was incurred in the category I drugs which was comparable to other studies.

Rational use of drugs along with restriction on non- essential drugs (category III), and imposition of fixed budget to this category is expected to bring about substantial savings without affecting patient care. Since only $1.2 \%$ of the drug budget was spent on category III drugs, it can be said that inventory management practice was appropriate. Thus, the managers had an option of either saving time by restricting their attention to $10 \%$ of drugs ('A' category in ABC analysis) or assured availability of the needed $85 \%$ of drugs ('V' and ' $\mathrm{E}$ ' categories of VED analysis). However, if they resort to the ABC-VED matrix, they could achieve both time saving and assured availability of needed drugs by closely supervising category I drugs that comprise $40 \%$ of all drugs. We feel the third option i.e. ABC-VED matrix analysis is the optimal way of managing drugs at secondary level hospital.

Almost all of the existing literature is from tertiary care settings. We could not locate any publication from India that was done in a secondary care setting. Hence, we are forced to compare our findings with that of tertiary care setting. A secondary care setting is different from tertiary health care facilities. A secondary care setting is likely to be significantly different from a tertiary care, in terms of, morbidity profile of patients, number of in-referrals for super-specialist care, and approach to health care i.e. preventive, promotive, or curative. Thus, the number, type and quantum of drug requirement would be different between the two settings.

An online list of drugs and supplies was displayed on Haryana Government website which also contained the quantity available, and their unit cost. The hospital administrator was authorized to indent drugs and supplies to a maximum of India Rupees 1,50,000 per month. This resulted in instances of indenting drugs in excess of actual monthly requirement so as to- 1) exhaust the sanctioned monthly quota of money, and 2) store the for future use when a particular drug might become unavailable. Thus, some of the drugs that were not needed at a given point of time but were available were procured. However, these stances were infrequent and are likely to vitiate the findings in a significant manner.

\section{CONCLUSION}

We therefore conclude that an ABC-VED matrix analysis system is an optimal drug inventory management system at a secondary health care setting.

\section{ACKNOWLEDGEMENT}

We acknowledge the store in-charge and pharmacists of the sub-divisional hospital, Ballabgarh, Haryana for their kind support in providing the required information.

Journal of Young Pharmacists Vol 7 • Issue 2 • Apr-Jun 2015 


\section{REFERENCES}

1. Introduction to medical equipment inventory management $\mathrm{WHO}$ Medical device technical series.2011. Available from digicollection. org/hss/en/cl/CL13.1.3.7/clmd,50.html

2. Kant S, Pandav CS, Nath LM. A management technique for effective management of medical store in hospitals. Medical store management technique. J Acad Hosp Adm. 1996 -1997; 8(9): 41-7.

3. Pillans PI, Conry I, Gie BE. Drug cost containment at a large teaching hospital. Pharmacoeconomics 1992; 1(5): 377-82.

4. Vaz FS, Ferreira AM, Kulkarni MS, Motghare DD. A study of drug expenditure at a tertiary care hospital: An ABC VED analysis. J Health Manag. 2008; 10(1): 119-27.

5. Gupta S, Kant S. Inventory control. In: Hospital stores management
- An integral approach. New Delhi: Jaypee Brothers Medical Publishers (P) Ltd; 2000. P. 60-72.

6. Kant S, Misra P, Gupta S, Goswami K, Krishnan A, Nongkynrih B, et al: Cohort Profile: The Ballabgarh Health and Demographic Surveillance System (CRHSP-AIIMS). Int J Epidemiol. 2013 Jun; 42(3): 758-68.

7. Online Drug Inventory and Supply Chain Management system, Government of Haryana. Available at www.dpmuhry.gov.in Accessed on 06th Nov 2014

8. Indian Public Health Standards. National Health Mission. Available at http://nrhm.gov.in/nhm/nrhm/guidelines/indian-public-healthstandards.html Accessed on 06th Nov 2014 